\title{
Identification and Utilization of Donor and Recipient Genetic Variants to Predict Survival After HCT: Are We Ready for Primetime?
}

\author{
Lara E. Sucheston-Campbell • Alyssa Clay • \\ Philip L. McCarthy • Qianqian Zhu • Leah Preus • \\ Marcelo Pasquini • Kenan Onel • Theresa Hahn
}

Published online: 21 February 2015

(C) The Author(s) 2015. This article is published with open access at Springerlink.com

\begin{abstract}
Overall survival following hematopoietic cell transplantation (HCT) has improved over the past two decades through better patient selection and advances in HLA typing, supportive care, and infection prophylaxis. Nonetheless, mortality rates are still unsatisfactory and transplant-related mortality remains a major cause of death after unrelated allogeneic HCT. Since there are no known pre-HCT, non-HLA biologic predictors of survival following transplant, for over a decade, scientists have been investigating the role of non-HLA germline genetic variation in survival and treatment-related mortality after HCT. Variation in single nucleotide polymorphisms (SNPs) has the potential to impact chemotherapy, radiation, and immune responses, leading to different post-HCT survival outcomes. In this paper, we address the current knowledge of the contribution of genetic variation to survival
\end{abstract}

This article is part of the Topical Collection on Stem Cell Transplantation

L. E. Sucheston-Campbell $(\bowtie) \cdot$ A. Clay $\cdot$ L. Preus

Department of Cancer Prevention and Control, Roswell Park Cancer Institute, Elm and Carlton Streets, Buffalo, NY 14263, USA

e-mail: Lara.Sucheston@roswellpark.org

P. L. McCarthy $\cdot$ T. Hahn $(\triangle)$

Department of Medicine, Roswell Park Cancer Institute, Elm and Carlton Streets, Buffalo, NY 14263, USA

e-mail: Theresa.Hahn@roswellpark.org

Q. Zhu

Department of Biostatistics, SUNY-Buffalo, Buffalo, NY, USA

M. Pasquini

Center for International Blood and Marrow Transplant Research, Medical College of Wisconsin, Milwaukee, WI, USA

K. Onel

Department of Pediatrics, The University of Chicago, Chicago, IL, USA following HCT and discuss study design and methodology for investigating HCT survival on a genomic scale.

Keywords Hematopoietic cell transplantation (HCT) · HLA typing $\cdot$ Infection prophylaxis $\cdot$ Non-HLA biologic predictors . SNPs

\section{Introduction}

The most successful curative therapy for many malignant hematologic diseases is hematopoietic cell transplantation (HCT). However, the success of this treatment is limited by transplant-related mortality (TRM). Better patient selection and advances in HLA typing combined with supportive care and infection prophylaxis have improved survival over the past two decades $[1,2 \cdot 3]$. Nonetheless, TRM remains a major cause of death, with disease-related mortality (DRM) the other largest contributor [4]. Although several clinical variables, including disease status at transplant, stem cell source, graft source, and CMV status are associated with survival outcomes [3], there are currently no established genetic predictors of survival after transplantation outside of $H L A$ matching. Variation in single nucleotide polymorphisms (SNPs) may lead to differential gene transcription, translation, and protein structure. These changes have the potential to modify immune responses or side effects of chemotherapy and/or radiation, and thus, survival outcomes in HCT patients [5, 6]. Various candidate genes have been tested for association with survival outcomes. Variants have been selected in genes relating to immune response to infection and inflammatory reactions, with the goal of understanding the biological basis of TRM 
and DRM and ultimately developing a better understanding of individual risk conveyed by genomic loci outside $H L A$. In studies of allogeneic HCT outcomes, the individual and joint effects of recipient and donor genotypes have been tested with the intent of developing a clinically applicable donor selection strategy to improve transplant success [7-9]. Another approach has focused on selecting and evaluating SNPs in genes within drug metabolism/detoxification pathways. By demonstrating genetic associations with transplant outcomes after exposure to various chemotherapeutic agents or combinations, the potential to assign a conditioning regimen based on genotype becomes a possibility $[10,11]$. To date, these candidate gene approaches have not been conclusive, in part due to sample size limitations and marked heterogeneity in population, disease, HLA matching, donor, and graft source. The objective of this article is to understand where studies of germline genetic variation have taken the transplant field in the hunt for clinically valid and actionable genetic variation associated with survival after HCT and how using genomics, versus genetics, may lead to better outcomes for patients $[12 \bullet, 13]$. We focus only on the role of germline genetic variation on survival after transplant since other studies have eloquently reviewed SNP associations with outcomes such as susceptibility to leukemia and chemotherapy toxicity [14] and the incidence and severity of graft-versus-host disease (GvHD) [15••]. We address current knowledge about the contribution of germline SNPs to survival following allogeneic $\mathrm{HCT}$, first reviewing the published evidence for a role of non- $H L A$ genetics in survival following transplant irrespective of, and considering, chemotherapeutic exposures. We then consider where these studies are in the translational research continuum and discuss genomic study design and methodological considerations when measuring competing risk outcomes.

\section{Overview of Associations of Candidate Genes with Survival After HCT}

Candidate gene studies have tested SNP associations with cause-specific (TRM and DRM) and overall survival in redox metabolism genes (GSTM1, UGT2B17) [16, 17] and cytokine and chemokine genes and their receptors (IL7 receptor- $\alpha, I L-$ 10 and $T N F-\alpha, I L-1, I L-1-\beta, I L-1-\alpha, I L-6, I L-10, I L-10 R, I L-$ 23, IL23R, CCL2, CCR5, TLR9) in both donors and recipients [18-30]. Other studies focused on variants in genes responsible for immune response and recognition including FCGR3A [31], CTLA4 [23, 24, 32-35], LCT [36], and NOD2/CARD15 [37-49], as well as VDR [50-54] and MTHFR [54, 55] and $T H B D$ [56]. Initial results were promising, reviewed in [57], and yielded some significant associations with overall survival (OS) and TRM after related and unrelated donor HCT. However, follow-up studies did not replicate SNP associations with outcomes, either because the initial study population was so small the association was false, the replication was equally small, and/or the follow-up was not rigorously designed for replication [23, 38, 45-47].

\section{Associations of NOD2/CARD15 with Survival After HCT}

An excellent example of this is NOD2/CARD15, selected for study in transplant outcomes as SNPs in NOD2/CARD15 were found to be associated with Crohn's disease, and there are similarities in this chronic inflammatory disorder of the gastrointestinal tract and GvHD symptoms. Few genes have been studied so extensively in relation to HCT with so many conflicting results, reviewed in [58]. While the initial association with an increased risk of TRM [42] was confirmed by a few studies [40, 44, 48], multiple other studies showed no association with survival following HCT [38, 45, 46, 59], with additional work hinting that perhaps results varied by use of $\mathrm{T}$ cell-depleted grafts [43]. The largest NOD2/CARD15 study to date, 567 donor-recipient pairs both HLA matched and mismatched with primary diagnoses including hematologic malignancies, non-hematologic malignancies, and nonmalignant diseases, found only a borderline association ( $p=.049)$ of a recipient SNP with increased TRM and conflicting results in the non-malignant patient groups [60].

Collectively, these SNP-survival association studies appear to be dependent on the combination of transplant regimen, donor cell source, disease, and HLA matching and even further compounded by the fact that SNP frequencies vary significantly by race and ethnicity $[61,62]$. The intrinsic complexity of these results is further obfuscated as estimates of effect size and $p$ values were obtained from prohibitively small studies, in most cases with 100-200 patients. In addition, only limited variants in this region were studied for associations with TRM, DRM, or OS. Given the polymorphic nature of NOD2 and the varying linkage disequilibrium structure by race and ethnicity [58], a more thorough investigation in homogenous appropriately sized populations is needed.

This extensive body of work is an excellent illustration of the consequences of heterogeneity and small sample size on studies of the relationship of germline genetics with survival following HCT. Definitive results from large-scale and replicated genetic studies are an imperative first step to finding clinically valid, and ultimately clinically actionable, variants for incorporation in treatment planning [12••, 63].

\section{Pharmacogenetic Associations with Survival after HCT}

Busulfan $(\mathrm{Bu})$ and cyclophosphamide (Cy), the most commonly used alkylators in high-dose conditioning regimens prior to HCT, are associated with inter-individual variation in both relapse and toxicity [64]. While the unpredictable metabolism of these agents can lead to unintentional overdosing, an alternative explanation for excessive toxicity and 
differential adverse effects among patients given a $\mathrm{Bu} / \mathrm{Cy}$ conditioning regimen is genetics [65]. SNPs in the CYP450 and glutathione enzyme families have been shown to affect clinical outcomes, relapse, and drug-related toxicities after $\mathrm{HCT}$. Specifically response to $\mathrm{Cy} / \mathrm{Bu}$ has been hypothesized to be due to variation in $\mathrm{Cy}$ metabolism by $C Y P 2 B 6$ and $C Y P 2 C 19$ which activates $\mathrm{Cy}$ to 4hydroxy Cy [66, 67] and metabolizing enzymes involved in $\mathrm{Bu}$ conjugation, namely glutathione $S$-transferase (GST) isoenzymes A1 (GSTA1) and M1 (GSTM1). However, as with the studies of survival-SNP associations, pharmacogenetic studies of survival after HCT are plagued with inconsistencies due to small sample sizes compounded by the heterogeneity in exposure (drug) and dose.

\section{Association of the $C Y P$ Gene Family with Survival}

CYP2C19 encodes a well-characterized and highly polymorphic enzyme that metabolizes Cy (among other drugs). Individuals can be grouped into poor (PM), intermediate (IM), and extensive (EM) metabolizers by presence or absence of active enzymes. PM $(C Y P 2 C 19 * 2 / * 2, * 2 / * 3$, and *3/*3) metabolize drugs more slowly, show prolonged side effects [68, 69], and have a higher rate of TRM, but no association was seen with OS [59]. Although this was one of the larger studies of TRM, the low frequency of PM (approximately $3 \%$ of the study population) necessitated a design with considerably larger sample sizes for the appropriate statistical power to detect the true effect size. Subsequent examinations of CYP2C19 have again suffered from the tyranny of small numbers. Melanson et al. [70] redefined the CYP2C19, PM and IM classification previously used [59] and showed associations of CYP2C19*2/*2 with worse progression-free survival (PFS) and OS but not with non-relapse mortality. This could be due to myeloablative doses of conditioning, the sequence of conditioning regimen drugs, or interactions with other drugs which may diminish or alter the detectable genetic effects. Consistent genetic and phenotype definitions are imperative for replications.

CYP2B6 is also an important enzyme that helps determine the rate of $\mathrm{Cy}$ clearance; however, only suggestive associations with survival following HCT have been shown among individuals who are considered ultra-rapid metabolizers, but no impact was seen on overall survival [70]. As with the CYP2C19 extensive metabolizer group, the $C Y P 2 B 6$ variants defining ultra-rapid metabolizers were not common, yielding a small comparison group. These CYP studies, like the NOD2/CARD15 research, highlight the importance, and challenge, in designing appropriately sized discovery and replication studies.
Association of Glutathione S-transferase (GST) Superfamily with Disease-Free Survival

Bu-containing conditioning regimens show even greater interpatient variability in efficacy and toxicity than $\mathrm{Cy}$. Intravenous vs oral administration of $\mathrm{Bu}$, as well as differences in GI absorption, can generate variability in pharmacokinetics, drug clearance and drug activity. Therefore, patients receiving myeloablative $\mathrm{Bu}$ prior to HCT have therapeutic drug monitoring as standard clinical practice [71]. A high Bu steady-state plasma concentration can be toxic, whereas low concentrations are associated with poor engraftment and higher relapse risk [72]. Consequently, clinical outcomes are improved by targeting plasma concentrations and thus variants in the predominant metabolizing enzymes involved in Bu conjugation, glutathione $S$-transferase (GST) isoenzymes A1 (GSTA1) and M1 (GSTM1), have been tested for association with survival after transplant [10, 17, 54, 66-68, 72-75]. Yee et al. found a SNP in the GSTM1-GSTM5 locus, rs3754446, associated with an almost twofold shorter diseasefree survival in two cohorts of acute myeloid leukemia (AML) patients treated with chemotherapy-based autologous HCT. Despite replicating in both cohorts $(p=.001$ and $p=.028)$, the finding was not significant after correction for multiple testing [10]. The authors found similar relationships with rs4148405 in $A B C C 3$, although while passing multiple testing correction in cohort $1(p<10 \mathrm{e}-06)$, it did not replicate in cohort 2 . Additional genetic association studies have provided some evidence that variants in the genes in the ATP-binding cassette $(A B C)$ family are associated with outcome $[75,76]$.

While other adverse associations with GSTM polymorphisms have been shown with transplant-related toxicities [74] and in other cancers, reviewed in [77], the GSTM1 associations seen by Yee et al. have not replicated [54, 74]. Again this could be due to the population studied (Rocha et al. analyzed associations in HLA-identical sibling donor-recipient pairs, while Hahn et al. analyzed overall survival in groups of autologous and related and unrelated donor allogeneic patients), the small heterogeneous sample sizes, the differences in the exact GSTM variation studied, or even subtle population substructure.

It is important to note that while this pharmacogenetic research is inconclusive, these drug metabolism pathways are well established and thus merit further investigation in larger cohorts. This approach has been done previously with success in relation to genetic associations with GvHD following HCT [78].

In 2007, an article in Blood was published, highlighting the rationale for a genome-wide approach in studying hematologic etiology and disease outcome [79•], and scientists have eagerly moved in this direction [15••]; however, since this time, only candidate gene studies have been published (Table 1). Of these, only two have replicated significant findings in a second independent population and one result has demonstrated enough validity to pursue clinical application in a multicenter trial currently underway. 


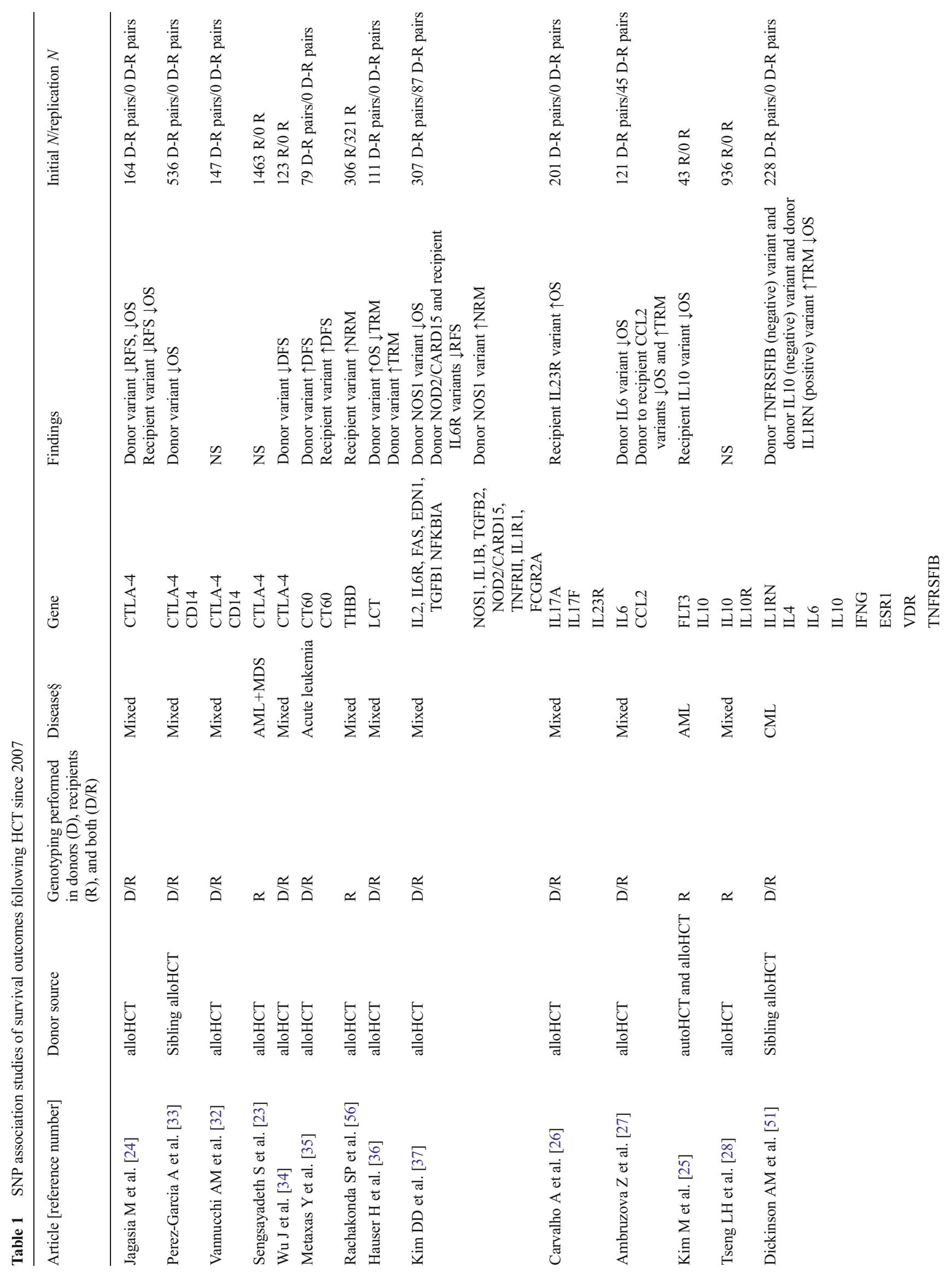




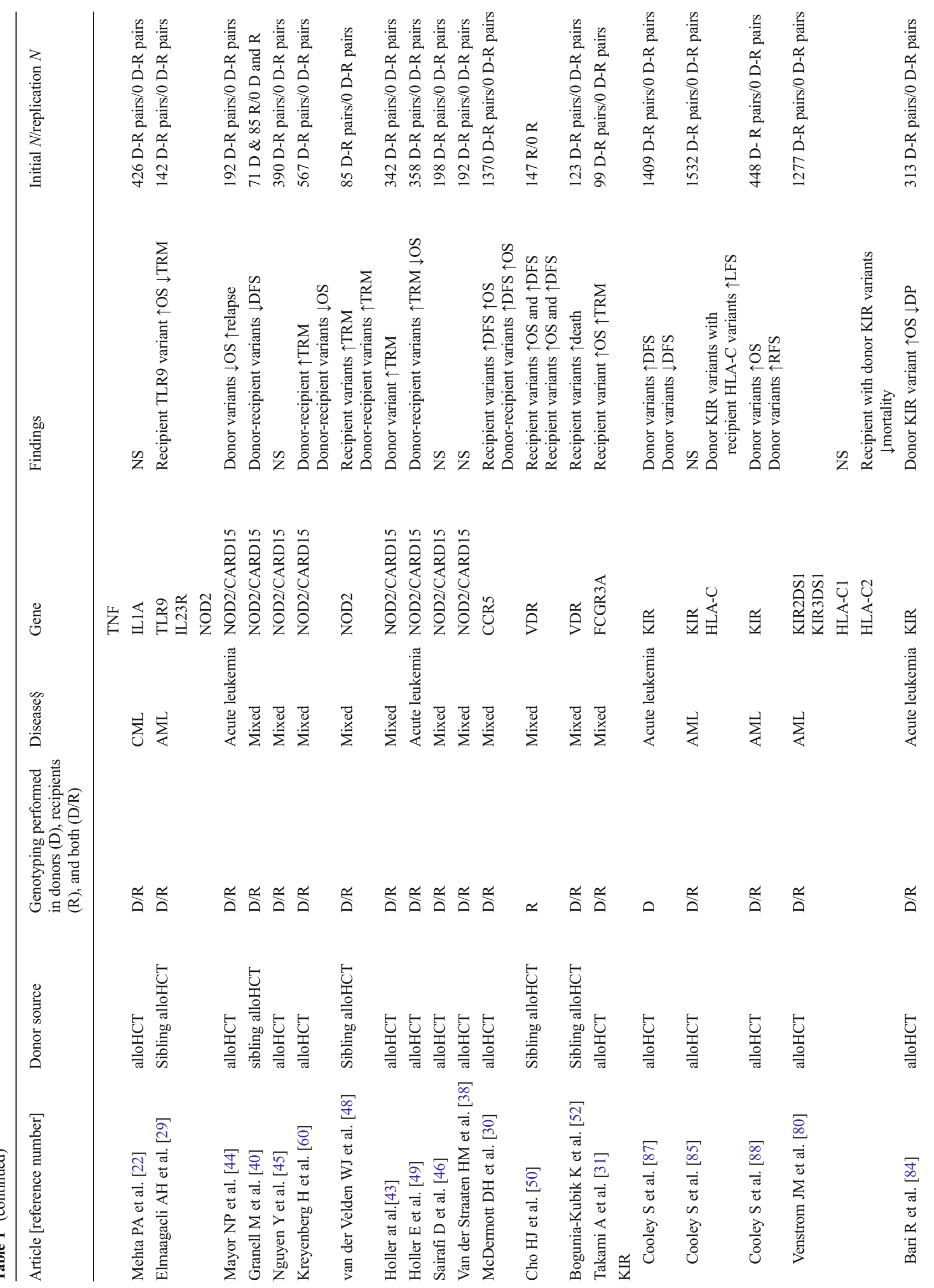




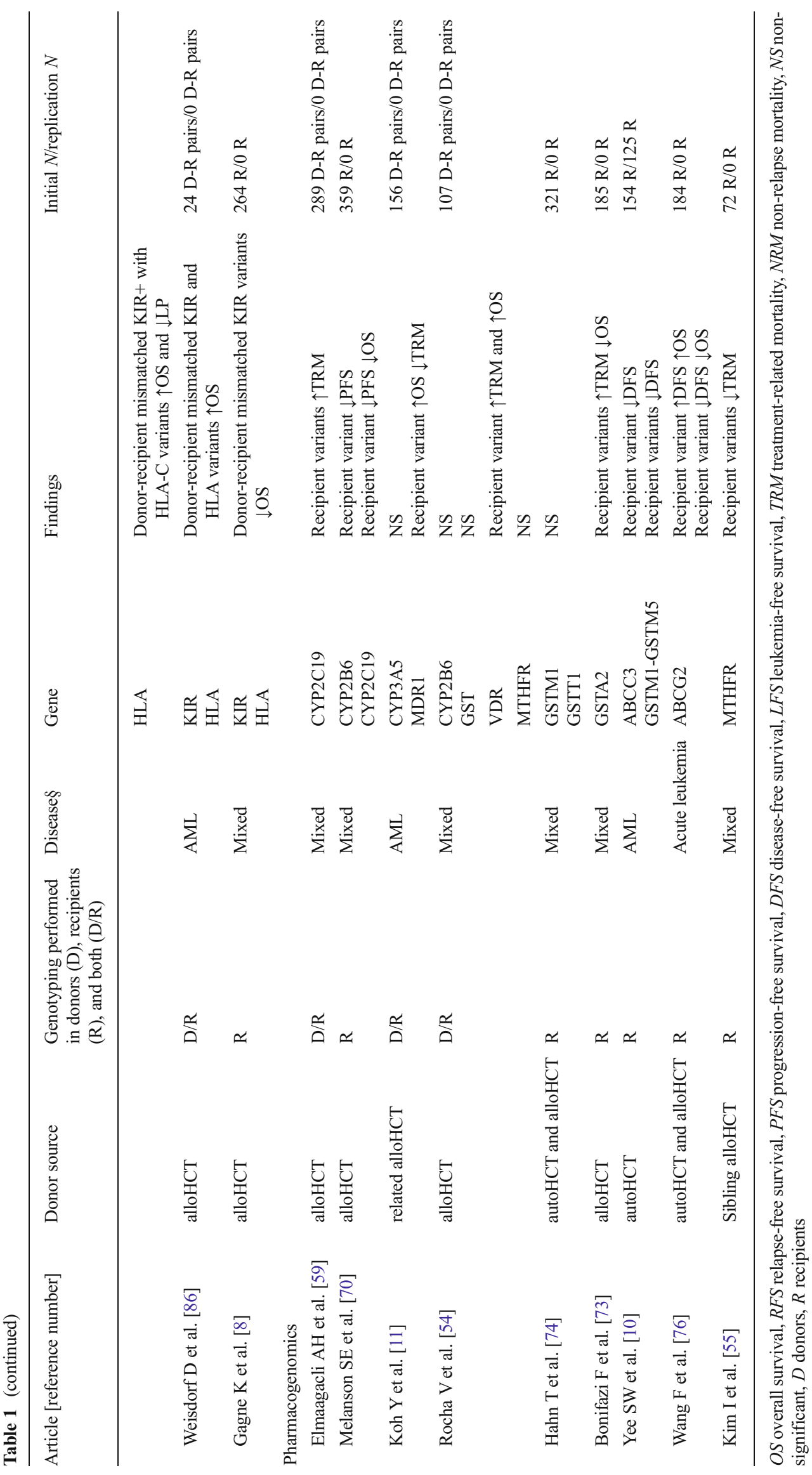


Independent and Joint Effects of KIR and HLA-C in AML Patients Treated with alloHCT

The polymorphic killer-cell immunoglobulin-like receptors (KIRs) recognize KIR ligands. HLA molecules activate KIR receptors at the cell surface and therefore are considered KIR-ligands. The KIR ligands are grouped into three major categories based on the amino acid sequence determining the KIRbinding epitope in HLA-C and HLA-B molecules. All expressed $H L A-C$ alleles are of the $\mathrm{C} 1$ or $\mathrm{C} 2$ group and most $H L A-B$ alleles can be classified as either Bw4 or Bw6 [80, 81]. This HLA-KIR interaction was first explored in HLA haploidentical transplantation [73] and later investigated in other allogeneic donor settings in hopes it may stimulate GVL reactions in HCT [81-84]. More recently, survival outcomes under varying combinations of donor genetic variation in $K I R$ and recipient HLA class I have been tested [84-89••]. These studies focused on AML outcomes after an unrelated donor HCT (URD-HCT) in pediatric and adult patients and have shown similar results in both the direction and magnitude of the impact of the KIR donor genotype on survival outcomes. Therefore, a prospective clinical trial incorporating $K I R$ genotyping into URD selection for AML is currently accruing patients (http://www.clinicaltrials.gov/ ,NCT01288222). This is the first clinical trial of HCT outcomes involving non- $H L A$ genetics and is the result of consecutively larger studies rigorously demonstrating a genetic association in homogenous study populations.

$K I R$ can be broadly categorized into two haplotypes [90-92]: the A haplotype, with at most a single activating gene, KIR2DS4, and the B haplotype, with KIR2DS4 plus at least one of the following activating genes: KIR $3 D S 1, K I R 2 D S 2$, $K I R D S 3$, or KIRDS5. Individuals who are $B / x$ (either $B / B$ or heterozygous $B / A$ ) are described as having an activating $K I R$ genotype. The first study to demonstrate an association of recipient outcome with KIR activating genes included 209 HLAmatched and 239 HLA-mismatched T-replete URD-HCT for AML [88]. Three-year overall survival was significantly higher after transplantation from a $K I R \mathrm{~B} / \mathrm{x}$ donor afforded the recipients better overall and relapse-free survival when compared with A/A donors. The protective effect of donor $B / x$ genotype was replicated in a larger cohort of early, intermediate, and advanced AML undergoing T-replete URD-HCT $(n=1086)$. However this advantage was not seen in acute lymphoblastic leukemia (ALL) patients $(n=323)$.

\section{HLA-KIR Interactions Associated with Survival After HCT}

The KIR locus contains genes that are centromeric $(\mathrm{Cen})$ and telomeric ( $\mathrm{Tel}$ ). Dividing the B/x haplotype into $\mathrm{Cen}$ and $\mathrm{Tel}$ segments showed that the $B$ haplotype genes in the $C e n$ region had a stronger effect in improving the overall survival after transplantation than those in the $\mathrm{Tel}$ region. Specifically, individuals who were $C e n-B / B / T e l-X / X(K I R 2 D S 2$ and/or $K I R 2 D L 2$, no $K I R 2 D L 3 / X$ ) versus $C e n-A / A / T e l-X / X$ $(K I R 2 D L 3$ only/X) showed an increase in overall and disease-free survival. Again, no KIR effect was seen for ALL patients [87]. While promising, the proportion of Cen$B / B$ patients in the study was $11 \%$. When the cohort was expanded to include almost 500 additional AML patients $(N=1532)$, the association of leukemia-free survival (LFS) with donors having two or more $B$ motifs was maintained. In addition to testing the $\mathrm{B}$ motif association, the authors sought to assess donor KIR-HLA recipient combinations with outcome [85]. Individuals who are $C e n-B / B$ have activating $K I R$ genes that encode inhibitory KIRs specific for the $C l$ and $C 2$ epitopes of $H L A-C$. The authors examined the interaction between donor KIR B genes and recipient class I HLA KIR ligands and found transplants mismatched at $H L A-C 1$ experienced an almost twofold reduction in LFS by the KIR $B / x$ donor. Interestingly this survival advantage in $C 1 / x$ recipients compared with $C 2 / C 2$ recipients was similar irrespective of the donor KIR B status. Unlike the frequency of $C e n-B / B$ in the population, approximately $85 \%$ of the US population is $H L A C l / x$, thus making these findings very generalizable to the transplant population.

While these studies assessed KIR haplotypes, it has been shown that both OS and TRM are affected by individual activating KIRs in the Tel region, KIR3DS1 and KIR2DS1 [89••, 93], and that like the motifs, these individual KIR may interact with recipient $H L A$. Venstrom et al. [89••] found that donor KIR2DS1 positive with $H L A-C 1 / x$ conferred increased survival benefits (similar in effect size seen in $C e n-B / B$ with $H L A$ $C / x$ ) while KIR3DS1 impacted survival but donor HLA-C match or mismatch had no enhanced effect. Thus, it appears that both independent and joint donor and recipient genetics impact survival, making it particularly important to better understand this complex interplay in large comprehensive studies.

Selecting a Favorable KIR Donor in Unrelated HCT for AML

A prospective trial is currently accruing to test and validate the efficacy of choosing an URD for HCT based on KIR genotyping. Up to $600 \mathrm{AML}$ patients will be enrolled to determine whether prospective selection of URDs based on a favorable KIR donor will reduce the cumulative incidence of relapse and improve LFS and overall survival. Preferred $K I R$ donors are selected on the basis of a $\mathrm{B}$ content score. The KIR B-content score for each donor's KIR genotype is defined as the number of centromeric and telomeric genecontent motifs containing B haplotype-defining genes and is classed as "Best", "Better" or "Neutral". This trial is not considering HLA-C/x donor variation. Once completed, this trial will provide the first prospective evidence on the 
utility of non- $H L A$ genotypes to improve survival after URD-HCT for AML.

\section{Are We Ready for Primetime?}

To understand where these genetic studies have led the transplant field, we consider this research in a useful framework for characterizing the spectrum of translational research [12••]. It is important to not think of these phases as linear but rather as on a continuum, accessible at any point on the path to identifying, quantifying, and characterizing the relationship of genomics with survival after HCT. Four phases (T1-T4) comprise the framework, with $\mathrm{T} 0$ representing the discovery of new variant associations and other biomarkers of outcome following HCT. In the $\mathrm{T} 1$ phase, results from $\mathrm{T} 0$ are moved towards the implementation of interventions or diagnostic tests, e.g., evaluation of the function of genomic variants and analyses of gene-exposure interactions. T2 research is the clinical intervention used to determine if the proposed application of T1 findings is better than the standard of care. The KIR genomics studies began as $\mathrm{T} 0$ and moved into $\mathrm{T} 1$, and the trial is at present in $\mathrm{T} 2$. T3 assesses how to implement and integrate T2, e.g., should KIR-HLA matching improve overall survival, we must determine how this can be implemented into clinical practice at transplant centers nationwide. Lastly, the population health impact of implementation is evaluated in T4, e.g., what the overall reduction is in death attributable to the introduction of KIR matching in HCT.

Most of genomic variation research related to HCT survival is at the T0 and maybe T1 level; however, it is important to realize that while these are the first steps to translating results to routine clinical practice, it is also imperative researchers are simultaneously working with the fields of health economics, comparative effectiveness, disparities, and bioethics in an effort to understand and reduce barriers that will prevent the successful application of non-HLA genomics to transplant [63]. One example of opportunities in this arena rests with the scientists working in the field of statistical genetics. High-resolution typing is expensive and time consuming. To combat this time and cost issue, for the last decade, researchers have focused on the development of statistical methods to impute HLA regions with a high degree of accuracy [94]. In the European-American population for classical HLA class I and class II genes, there is approximately $97 \%$ accuracy [95], and these methods are rapidly expanding to include other races and ethnic groups $[96,97]$. There are a number of translational research opportunities deriving from this $\mathrm{T} 1$ phase work, and with the accessibility of sequencing increasing, this work may move quickly through T2, as precision can be shown with studies in large sample sizes, and on to T3 and T4, implementation, e.g., where we must consider the how, where, and how much. We should not wait to think about these problems of implementation and assessment but rather understand the contribution and value of this particular research as it is moving towards clinical validation.

\section{Genome-Wide Association Study of Survival After HCT}

While heterogeneity and small sample sizes have plagued many of these studies, there is clear translational potential and further exploration of the contribution of non-HLA genetic variation in the recipient and/or donor to the risk of mortality after HCT is warranted. To examine this hypothesis in a well-sized and welldefined study population, we have begun a genome-wide association study (GWAS) to investigate the joint and independent genetic factors in recipients and donors contributing to death after URD-HCT, called Determining the Influence of SusceptibilityCOnveying Variants Related to 1-Year mortality after unrelated donor Blood and Marrow Transplant (DISCOVeRY-BMT). The two independent cohorts used for analyses include patients diagnosed with AML, ALL, or myelodysplastic syndrome (MDS), reported to the Center for International Blood and Marrow Transplant Research (CIBMTR) with a banked National Marrow Donor Program (NMDP) biorepository sample available for both

Table 2 DISCOVeRY-BMT study design

\begin{tabular}{|c|c|c|c|}
\hline Genetic variation & Study population & Exposure & $\begin{array}{l}\text { Survival outcomes: overall, } \\
\text { TRM and DRM }\end{array}$ \\
\hline \multirow{3}{*}{$\begin{array}{l}\text { Common (Illumina Omni Express } \\
\text { chip+imputation) and rare (Illumina } \\
\text { Exome chip) genetic variation }\end{array}$} & \multirow{3}{*}{$\begin{array}{l}\text { Donor and recipient pairs } \\
\text { in two cohorts }(\mathrm{C} 1=2601 \text {, } \\
\mathrm{C} 2=923)\end{array}$} & - & AIM 1 \\
\hline & & $\begin{array}{l}\text { Non-myeloablative therapy versus } \\
\text { myeloablative therapy }\end{array}$ & AIM 2 \\
\hline & & $\begin{array}{l}\text { Cyclophosphamide } \\
\quad+\text { Total body irradiation versus } \\
\text { +busulfan }\end{array}$ & AIM 3 \\
\hline
\end{tabular}

The DISCOVeRY BMT study design includes analyses of common and rare genetic variation in two cohorts. Specifically, we are undertaking a GWAS to map the independent and joint effects of recipient and donor genetic variation associated with survival outcomes after HLA-matched unrelated donor BMT in thousands of donor-recipient pairs. The purpose of specific aims 2 and 3 are to determine if conditioning regimens modify associations between recipient and/or donor genetic variants and TRM in the same population as aim 1 
the recipient and donor. Cohorts 1 and 2 include 2609 10/10 HLA-matched, T cell-replete, URD-HCT recipients treated from 2000 to 2008 and 923 8/8 HLA-matched, T cell-replete, URDHCT recipients treated from 2000 to 2011, respectively. Of the 2609 patients, 1116 (43\%) died before 1-year post-transplant, and of the 923 patients, 368 (40\%) died before 1-year post-HCT.

\section{Competing Risk Models in GWAS}

To analyze TRM, we must consider that TRM and DRM are competing risks for the outcome of death [98•]. Broadly, two approaches can be used to model competing risks: causespecific hazard functions, constructed using a Cox proportional hazard model, defining causes other than the one we are interested in as censored failures, or we can model the cumulative incidence functions of the different event types using a subdistribution hazard model which takes into account competing risks rather than merely censoring them [99]. The modeling of the cause-specific hazards is appropriate when the goal is to assess if a factor is associated with the risk of a specific cause of failure. However, when the goal is to compare the observed incidence of events from a given cause between groups, the subdistribution hazard should be used. Because the effect of a covariate on cause-specific hazard function for a particular cause can be different from its effect on the subdistribution function of the corresponding cause, the cause-specific hazard function and subdistribution can give different results [100, 101]. These two analyses both provide important information, and it is recommended both methods are used when measuring associations with competing risk [102]. However, of the studies reviewed (Table 1), more often than not only cause-specific hazard was done and not both. This inconsistency in approach can be remedied going forward by leveraging both methods to better understand the contribution of genetic variation to survival after HCT.

To date, competing risk events have not been analyzed on a genome-wide scale and are often thought of as unique to the HCT field. However, as cancer treatments improve and more follow-up data are available, being able to analyze rare and common variation using competing risk analyses will be necessary in order to assess the role of genetic variation in competing clinical outcomes. At present, existing software scaled for millions of analyses is not available to test competing risk events; therefore, we are in the process of building custom R statistical packages to analyze both common and rare genetic variations in this setting.

\section{DISCOVeRY-BMT Study Design and Power}

The study design is illustrated in Table 2. We present some example power calculations for assessing the hazard of TRM overall as well as gene-drug interactions under a competing risk hazard model. Given that the minimum number of TRM subtype deaths (death due to GvHD, infection, and organ failure) and overall TRM is between $10 \%$ and $40 \%$ and assuming a minor allele frequency (MAF) of 0.40 , we have excellent power to detect hazard ratios between 1.98 and 1.38 , respectively (Fig. 1). Considering a reduced population comprising only patients given myeloablative cyclophosphamide (either TBI or $\mathrm{Bu}$ ), approximately $70 \%$ of all patients in the first cohort, and assuming $40 \%$ of URD-HCT recipients experience TRM before 1-year post-transplant, we will have power to detect hazard ratios from 1.75 to 2.25 for MAF varying between $40 \%$ to $10 \%$, respectively. Unfortunately, in contrast to the relative homogeneity of myeloablative conditioning regimens used in URD-HCT (BuCY or CyTBI), reduced intensity/nonmyeloablative conditioning regimens are heterogeneous in both drugs and doses therefore precluding a well-powered GWAS. DISCOVeRY-BMT is a large homogeneous population

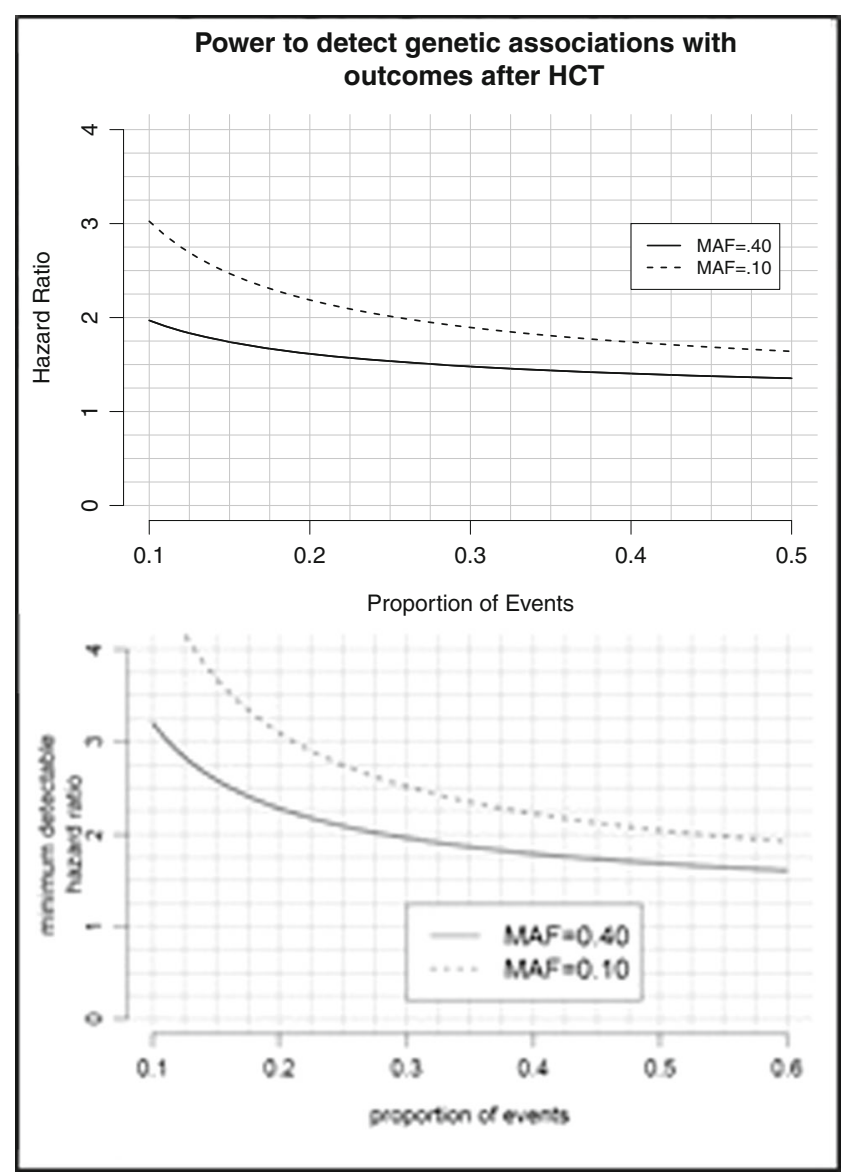

Fig. 1 Power to detect associations with DRM, TRM, and TRM subtypes is shown in the Fig. 1 . The $x$-axis, showing the proportion of events, can be used to determine power for a range of survival outcomes following HCT from 10 to $50 \%$ in frequency. The dashed and solid lines reflect minor allele frequencies of 0.10 and 0.40 , respectively. Thus, for example, given a survival outcome occurring in $25 \%$ of DISCOVeRYBMT cohort 1 and a minor allele frequency of 0.40 , we have power to detect hazard ratios of approximately 1.5. A lower MAF of 0.10 yields power to detect hazard ratios of 2.0 
that will be able to unambiguously identify clinically relevant hazards attributable to the joint and/or independent effects of genetic variation. Thus, it is the first step towards translating these data clinically and defining the biology of these devastating and poorly understood endpoints $[12 \bullet \bullet$.

\section{Conclusion}

The rapidly growing number of URD HCTs coupled with a high TRM yields an increasingly significant public health problem. Given TRM is the limiting factor to referring more potential patients and extending survival in existing patients, it is a clear target for translational research to increase the success and utilization of HCT as a curative therapy. So far, candidate gene studies have pursued discovery studies of genetic variation with the intent of making them clinically actionable but have had limited success in replication and thus are stuck in the T0 phase. When considering the KIR-HLA findings and the subsequent trial, we describe this as T2 research, with the understanding that the implementation (T3) and assessment of the impact (T4) will follow. Should this be successful, it will be the first demonstration that better matching using non-HLA alleles is not only possible but can also actively reduce death rates.

DISCOVeRY-BMT is also designed to identify polymorphisms in recipients and/or unrelated donors with the potential for better recipient-donor pairing, the identification of patients at risk for TRM, or a high probability of DRM (T1 phase) with the intent of moving through the continuum of translational research. Importantly, the data generated from this project will be made publicly available to provide a very unique resource of a highly specialized, curative therapy where many additional hypotheses can be tested or confirmed.

Acknowledgments This study was supported by grants from the National Heart, Lung, and Blood Institute (HL102278 to LSC and TH) and the National Cancer Institute (CA139426 supporting AC).

\section{Compliance with Ethics Guidelines}

Conflict of Interest Dr. Lara E. Sucheston-Campbell, Dr. Alyssa Clay, Dr. Philip L. McCarthy, Dr. Qianqian Zhu, Dr. Leah Preus, Dr. Marcelo Pasquini, Dr. Kenan Onel, and Dr. Theresa Hahn each declare no potential conflicts of interest.

Human and Animal Rights and Informed Consent This article does not contain any studies with human or animal subjects performed by any of the authors.

Open Access This article is distributed under the terms of the Creative Commons Attribution License which permits any use, distribution, and reproduction in any medium, provided the original author(s) and the source are credited.

\section{References}

Papers of particular interest, published recently, have been highlighted as:

- Of importance

•- Of major importance

1. Spellman S, Setterholm M, Maiers M, Noreen H, Oudshoorn M, Fernandez-Vina M, et al. Advances in the selection of HLAcompatible donors: refinements in HLA typing and matching over the first 20 years of the National Marrow Donor Program Registry. Biol Blood Marrow Transplant J Am Soc Blood Marrow Transplant. 2008;14(9 Suppl):37-44. doi:10.1016/j.bbmt.2008. 05.001.

2. Hahn T, McCarthy Jr PL, Hassebroek A, Bredeson C, Gajewski JL, Hale GA, et al. Significant improvement in survival after allogeneic hematopoietic cell transplantation during a period of significantly increased use, older recipient age, and use of unrelated donors. J Clin Oncol Off J Am Soc Clin Oncol. 2013;31(19): 2437-49. doi:10.1200/JCO.2012.46.6193. This study describes changes in allogeneic HCT use, technique and survival in over 38,000 patients over 12 years. The data show that over time, use of unrelated donor HCTs has increased in an older patient population with significant improvements in survival after HCT. These data provide a good argument for continuing to pursue nonHLA matching to further improve survival after URD-HCT.

3. Majhail NS, Chitphakdithai P, Logan B, King R, Devine S, Rossmann SN et al. Significant improvement in survival after unrelated donor hematopoietic cell transplantation in the recent era. Biol Blood Marrow Transplant. doi:10.1016/j.bbmt.2014. 10.001

4. Lee SJ, Klein J, Haagenson M, Baxter-Lowe LA, Confer DL, Eapen M, et al. High-resolution donor-recipient HLA matching contributes to the success of unrelated donor marrow transplantation. Blood. 2007;110(13):4576-83. doi:10.1182/blood-2007-06-097386.

5. Boyle AP, Hong EL, Hariharan M, Cheng Y, Schaub MA, Kasowski M, et al. Annotation of functional variation in personal genomes using RegulomeDB. Genome Res. 2012;22(9):1790-7. doi:10.1101/gr.137323.112.

6. Schaub MA, Boyle AP, Kundaje A, Batzoglou S, Snyder M. Linking disease associations with regulatory information in the human genome. Genome Res. 2012;22(9):1748-59. doi:10. 1101/gr.136127.111.

7. Loiseau P, Busson M, Balere ML, Dormoy A, Bignon JD, Gagne $\mathrm{K}$, et al. HLA association with hematopoietic stem cell transplantation outcome: the number of mismatches at HLA-A, $-\mathrm{B},-\mathrm{C}$, $-\mathrm{DRB} 1$, or -DQB1 is strongly associated with overall survival. Biol Blood Marrow Transplant J Am Soc Blood Marrow Transplant. 2007;13(8):965-74. doi:10.1016/j.bbmt.2007.04.010.

8. Gagne K, Busson M, Balere-Appert ML, Absi L, Jollet I, Bignon JD, et al. Relevance of KIR gene matching in unrelated hematopoietic stem cell transplantations. Tissue Antigens. 2007;69 Suppl 1:118-22. doi:10.1111/j.1399-0039.2006.76210.x.

9. Bignon JD, Gagne K. KIR matching in hematopoietic stem cell transplantation. Curr Opin Immunol. 2005;17(5):553-9. doi:10. 1016/j.coi.2005.07.014.

10. Yee SW, Mefford JA, Singh N, Percival ME, Stecula A, Yang K, et al. Impact of polymorphisms in drug pathway genes on diseasefree survival in adults with acute myeloid leukemia. J Hum Genet. 2013;58(6):353-61. doi:10.1038/jhg.2013.38.

11. Koh Y, Kim I, Shin DY, Bae JY, Kim HK, Yoon SS, et al. Polymorphisms in genes that regulate cyclosporine metabolism affect cyclosporine blood levels and clinical outcomes in patients 
who receive allogeneic hematopoietic stem cell transplantation. Biol Blood Marrow Transplant J Am Soc Blood Marrow Transplant. 2012;18(1):37-43. doi:10.1016/j.bbmt.2011.08.019.

12.• Khoury MJ, Gwinn M, Yoon PW, Dowling N, Moore CA, Bradley L. The continuum of translation research in genomic medicine: how can we accelerate the appropriate integration of human genome discoveries into health care and disease prevention? Genet Med Off J Am Coll Med Genet. 2007;9(10):665-74. doi:10.1097/GIM.0b013e31815699d0.This article presents a framework for considering the phases of genomics research and moving promising research into clinical practice.

13. Vora S, Ellis N, Onel K. Translating genetic questions into clinical answers in acute myeloid leukemia. Leuk Res. 2009;33(11):1448 9. doi:10.1016/j.leukres.2009.06.018.

14. Relling MV, Ramsey LB. Pharmacogenomics of acute lymphoid leukemia: new insights into treatment toxicity and efficacy. Hematol Educ Program Am Soc Hematol Am Soc Hematol Educ Program. 2013;2013:126-30. doi:10.1182/asheducation2013.1.126.

15.•• Hansen JA, Chien JW, Warren EH, Zhao LP, Martin PJ. Defining genetic risk for graft-versus-host disease and mortality following allogeneic hematopoietic stem cell transplantation. Curr Opin Hematol. 2010;17(6):483-92. doi:10.1097/MOH. 0b013e32833eb770.A thorough review of genetic association studies of GvHD and an outline of the next steps in studying genetic susceptibility to GvHD following HCT, including a large scale GWAS currently underway.

16. Terakura S, Murata M, Nishida T, Emi N, Akatsuka Y, Riddell SR, et al. A UGT2B17-positive donor is a risk factor for higher transplant-related mortality and lower survival after bone marrow transplantation. Br J Haematol. 2005;129(2):221-8. doi:10.1111/j. 1365-2141.2005.05427.x.

17. Terakura S, Murata M, Nishida T, Emi N, Akatsuka Y, Morishima $\mathrm{Y}$, et al. Increased risk for treatment-related mortality after bone marrow transplantation in GSTM1-positive recipients. Bone Marrow Transplant. 2006;37(4):381-6. doi:10.1038/sj.bmt. 1705257.

18. Shamim Z, Ryder LP, Heilmann C, Madsen H, Lauersen H, Andersen PK, et al. Genetic polymorphisms in the genes encoding human interleukin-7 receptor-alpha: prognostic significance in allogeneic stem cell transplantation. Bone Marrow Transplant. 2006;37(5):485-91. doi:10.1038/sj.bmt.1705277.

19. Keen LJ, DeFor TE, Bidwell JL, Davies SM, Bradley BA, Hows JM. Interleukin-10 and tumor necrosis factor alpha region haplotypes predict transplant-related mortality after unrelated donor stem cell transplantation. Blood. 2004;103(9):3599-602. doi:10. 1182/blood-2002-11-3568.

20. MacMillan ML, Radloff GA, Kiffmeyer WR, DeFor TE, Weisdorf DJ, Davies SM. High-producer interleukin-2 genotype increases risk for acute graft-versus-host disease after unrelated donor bone marrow transplantation. Transplantation. 2003;76(12):1758-62. doi:10.1097/01.TP.0000095899.54052.89.

21. MacMillan ML, Radloff GA, DeFor TE, Weisdorf DJ, Davies SM. Interleukin-1 genotype and outcome of unrelated donor bone marrow transplantation. Br J Haematol. 2003;121(4):597-604.

22. Mehta PA, Eapen M, Klein JP, Gandham S, Elliott J, Zamzow T, et al. Interleukin-1 alpha genotype and outcome of unrelated donor haematopoietic stem cell transplantation for chronic myeloid leukaemia. Br J Haematol. 2007;137(2):152-7. doi:10.1111/j.13652141.2007.06552.x.

23. Sengsayadeth S, Wang T, Lee SJ, Haagenson MD, Spellman S, Fernandez Vina MA, et al. Cytotoxic T-lymphocyte antigen-4 single nucleotide polymorphisms are not associated with outcomes after unrelated donor transplantation: a center for international blood and marrow transplant research analysis. Biol Blood
Marrow Transplant J Am Soc Blood Marrow Transplant. 2014;20(6):900-3. doi:10.1016/j.bbmt.2014.03.005.

24. Jagasia M, Clark WB, Brown-Gentry KD, Crawford DC, Fan KH, Chen $\mathrm{H}$, et al. Genetic variation in donor CTLA-4 regulatory region is a strong predictor of outcome after allogeneic hematopoietic cell transplantation for hematologic malignancies. Biol Blood Marrow Transplant J Am Soc Blood Marrow Transplant. 2012;18(7):1069-75. doi:10.1016/j.bbmt.2011.12.518.

25. Kim M, Kim J, Kim JR, Han E, Park J, Lim J, et al. FLT3 expression and IL10 promoter polymorphism in acute myeloid leukemia with RUNX1-RUNX1T1. Mol Biol Rep. 2014. doi:10.1007/ s11033-014-3786-1.

26. Carvalho A, Cunha C, Di Ianni M, Pitzurra L, Aloisi T, Falzetti F, et al. Prognostic significance of genetic variants in the IL-23/Th17 pathway for the outcome of T cell-depleted allogeneic stem cell transplantation. Bone Marrow Transplant. 2010;45(11):1645-52. doi:10.1038/bmt.2010.28

27. Ambruzova Z, Mrazek F, Raida L, Jindra P, Vidan-Jeras B, Faber E, et al. Association of IL6 and CCL2 gene polymorphisms with the outcome of allogeneic haematopoietic stem cell transplantation. Bone Marrow Transplant. 2009;44(4):227-35. doi:10.1038/ bmt.2009.16.

28. Tseng LH, Storer B, Petersdorf E, Lin MT, Chien JW, Grogan BM, et al. IL10 and IL10 receptor gene variation and outcomes after unrelated and related hematopoietic cell transplantation. Transplantation. 2009;87(5):704-10. doi:10.1097/TP. 0b013e318195c474.

29. Elmaagacli AH, Steckel N, Ditschkowski M, Hegerfeldt Y, Ottinger H, Trenschel R, et al. Toll-like receptor 9, NOD2 and IL23R gene polymorphisms influenced outcome in AML patients transplanted from HLA-identical sibling donors. Bone Marrow Transplant. 2011;46(5):702-8. doi:10.1038/bmt.2010.166.

30. McDermott DH, Conway SE, Wang T, Ricklefs SM, Agovi MA, Porcella SF, et al. Donor and recipient chemokine receptor CCR5 genotype is associated with survival after bone marrow transplantation. Blood. 2010;115(11):2311-8. doi:10.1182/blood-2009-08237768.

31. Takami A, Espinoza JL, Onizuka M, Ishiyama K, Kawase T, Kanda Y, et al. A single-nucleotide polymorphism of the Fcgamma receptor type IIIA gene in the recipient predicts transplant outcomes after HLA fully matched unrelated BMT for myeloid malignancies. Bone Marrow Transplant. 2011;46(2):23843. doi:10.1038/bmt.2010.88.

32. Vannucchi AM, Guidi S, Guglielmelli P, Glinz S, Lombardini L, Busca A, et al. Significance of CTLA-4 and CD14 genetic polymorphisms in clinical outcome after allogeneic stem cell transplantation. Bone Marrow Transplant. 2007;40(10):1001-2. doi: 10.1038/sj.bmt.1705850.

33. Perez-Garcia A, De la Camara R, Roman-Gomez J, JimenezVelasco A, Encuentra M, Nieto JB, et al. CTLA-4 polymorphisms and clinical outcome after allogeneic stem cell transplantation from HLA-identical sibling donors. Blood. 2007;110(1):461-7. doi:10.1182/blood-2007-01-069781.

34. Wu J, Tang JL, Wu SJ, Lio HY, Yang YC. Functional polymorphism of CTLA-4 and ICOS genes in allogeneic hematopoietic stem cell transplantation. Clin Chim Acta Int J Clin Chem. 2009;403(1-2):229-33. doi:10.1016/j.cca.2009.03.037.

35. Metaxas Y, Bertz H, Spyridonidis A, Spyroupoulou-Vlachou M, Porzelius C, Finke J. CT60 single-nucleotide polymorphism as a surrogate marker for donor lymphocyte infusion outcome after allogeneic cell transplantation for acute leukemia. Bone Marrow Transplant. 2012;47(3):411-5. doi:10.1038/bmt.2011.101.

36. Hauser H, Zach O, Krieger O, Kasparu H, Koenig J, Girschikofsky M, et al. A single nucleotide polymorphism at chromosome 2q21.3 (LCT $-13910 \mathrm{C}>\mathrm{T}$ ) associates with clinical outcome after allogeneic hematopoietic stem cell transplantation. 
Blood. 2008;112(5):2156-9. doi:10.1182/blood-2008-02139766.

37. Kim DD, Yun J, Won HH, Cheng L, Su J, Xu W, et al. Multiple single-nucleotide polymorphism-based risk model for clinical outcomes after allogeneic stem-cell transplantation, especially for acute graft-versus-host disease. Transplantation. 2012;94(12): 1250-7. doi:10.1097/TP.0b013e3182708e7c.

38. van der Straaten HM, Paquay MM, Tilanus MG, van Geloven N, Verdonck LF, Huisman C. NOD2/CARD15 variants are not a risk factor for clinical outcome after nonmyeloablative allogeneic stem cell transplantation. Biol Blood Marrow Transplant J Am Soc Blood Marrow Transplant. 2011;17(8):1231-6. doi:10.1016/j. bbmt.2010.12.709.

39. Madrigal A, Shaw BE. Immunogenetic factors in donors and patients that affect the outcome of hematopoietic stem cell transplantation. Blood Cells Mol Dis. 2008;40(1):40-3. doi:10.1016/j. bcmd.2007.08.004.

40. Granell M, Urbano-Ispizua A, Arostegui JI, Fernandez-Aviles F, Martinez C, Rovira M, et al. Effect of NOD2/CARD15 variants in T-cell depleted allogeneic stem cell transplantation. Haematologica. 2006;91(10):1372-6.

41. Holler E, Rogler G, Brenmoehl J, Hahn J, Herfarth H, Greinix H, et al. Prognostic significance of NOD2/CARD15 variants in HLAidentical sibling hematopoietic stem cell transplantation: effect on long-term outcome is confirmed in 2 independent cohorts and may be modulated by the type of gastrointestinal decontamination. Blood. 2006;107(10):4189-93. doi:10.1182/blood-2005-09-3741.

42. Holler E, Rogler G, Herfarth H, Brenmoehl J, Wild PJ, Hahn J, et al. Both donor and recipient NOD2/CARD15 mutations associate with transplant-related mortality and GvHD following allogeneic stem cell transplantation. Blood. 2004;104(3):889-94. doi: 10.1182/blood-2003-10-3543.

43. Holler E, Hahn J, Andreesen R, Rogler G, Brenmoehl J, Greinix $\mathrm{H}$, et al. NOD2/CARD15 polymorphisms in allogeneic stem-cell transplantation from unrelated donors: T depletion matters. J Clin Oncol Off J Am Soc Clin Oncol. 2008;26(2):338-9. doi:10.1200/ JCO.2007.14.1325. author reply 9.

44. Mayor NP, Shaw BE, Hughes DA, Maldonado-Torres H, Madrigal JA, Keshav S, et al. Single nucleotide polymorphisms in the NOD2/CARD15 gene are associated with an increased risk of relapse and death for patients with acute leukemia after hematopoietic stem-cell transplantation with unrelated donors. J Clin Oncol Off J Am Soc Clin Oncol. 2007;25(27):4262-9. doi:10. 1200/JCO.2007.12.1897.

45. Nguyen Y, Al-Lehibi A, Gorbe E, Li E, Haagenson M, Wang T, et al. Insufficient evidence for association of NOD2/CARD15 or other inflammatory bowel disease-associated markers on GVHD incidence or other adverse outcomes in T-replete, unrelated donor transplantation. Blood. 2010;115(17):3625-31. doi:10.1182/ blood-2009-09-243840.

46. Sairafi D, Uzunel M, Remberger M, Ringden O, Mattsson J. No impact of NOD2/CARD15 on outcome after SCT. Bone Marrow Transplant. 2008;41(11):961-4. doi:10.1038/bmt.2008.9.

47. Mayor NP, Shaw BE, Madrigal JA, Marsh SG. No impact of NOD2/CARD15 on outcome after SCT: a reply. Bone Marrow Transplant. 2008;42(12):837-8. doi:10.1038/bmt.2008.251.

48. van der Velden WJ, Blijlevens NM, Maas FM, Schaap NP, Jansen $\mathrm{JH}$, van der Reijden BA, et al. NOD2 polymorphisms predict severe acute graft-versus-host and treatment-related mortality in T-cell-depleted haematopoietic stem cell transplantation. Bone Marrow Transplant. 2009;44(4):243-8. doi:10.1038/bmt.2009.21.

49. Holler E, Rogler G, Brenmoehl J, Hahn J, Greinix H, Dickinson $\mathrm{AM}$, et al. The role of genetic variants of NOD2/CARD15, a receptor of the innate immune system, in GvHD and complications following related and unrelated donor haematopoietic stem cell transplantation. Int J Immunogenet. 2008;35(4-5):381-4. doi: 10.1111/j.1744-313X.2008.00795.x.

50. Cho HJ, Shin DY, Kim JH, Bae JY, Lee KH, See CJ, et al. Impact of vitamin D receptor gene polymorphisms on clinical outcomes of HLA-matched sibling hematopoietic stem cell transplantation. Clin Transpl. 2012;26(3):476-83. doi:10.1111/j.1399-0012.2011. 01523.x.

51. Dickinson AM, Pearce KF, Norden J, O'Brien SG, Holler E, Bickeboller $\mathrm{H}$, et al. Impact of genomic risk factors on outcome after hematopoietic stem cell transplantation for patients with chronic myeloid leukemia. Haematologica. 2010;95(6):922-7. doi:10.3324/haematol.2009.016220.

52. Bogunia-Kubik K, Middleton P, Norden J, Dickinson A, Lange A. Association of vitamin D receptor polymorphisms with the outcome of allogeneic haematopoietic stem cell transplantation. Int $\mathbf{J}$ Immunogenet. 2008;35(3):207-13. doi:10.1111/j.1744-313X. 2008.00758.x.

53. Middleton PG, Cullup H, Dickinson AM, Norden J, Jackson GH, Taylor PR, et al. Vitamin D receptor gene polymorphism associates with graft-versus-host disease and survival in HLA-matched sibling allogeneic bone marrow transplantation. Bone Marrow Transplant. 2002;30(4):223-8. doi:10.1038/sj.bmt.1703629.

54. Rocha V, Porcher R, Fernandes JF, Filion A, Bittencourt H, Silva $\mathrm{Jr} \mathrm{W}$, et al. Association of drug metabolism gene polymorphisms with toxicities, graft-versus-host disease and survival after HLAidentical sibling hematopoietic stem cell transplantation for patients with leukemia. Leukemia. 2009;23(3):545-56. doi:10. 1038/leu.2008.323.

55. Kim I, Lee KH, Kim JH, Ra EK, Yoon SS, Hong YC, et al. Polymorphisms of the methylenetetrahydrofolate reductase gene and clinical outcomes in HLA-matched sibling allogeneic hematopoietic stem cell transplantation. Ann Hematol. 2007;86(1):418. doi:10.1007/s00277-006-0184-3.

56. Rachakonda SP, Penack O, Dietrich S, Blau O, Blau IW, Radujkovic A, et al. Single-nucleotide polymorphisms within the thrombomodulin gene (THBD) predict mortality in patients with graft-versus-host disease. J Clin Oncol Off J Am Soc Clin Oncol. 2014;32(30):3421-7. doi:10.1200/JCO.2013.54.4056.

57. Dickinson AM, Middleton PG, Rocha V, Gluckman E, Holler E, Eurobank M. Genetic polymorphisms predicting the outcome of bone marrow transplants. Br J Haematol. 2004;127(5):479-90. doi:10.1111/j.1365-2141.2004.05216.x.

58. Mayor NP, Shaw BE, Madrigal JA, Marsh SG. NOD2 polymorphisms and their impact on haematopoietic stem cell transplant outcome. Bone Marrow Res. 2012;2012:180391. doi:10.1155/ 2012/180391.

59. Elmaagacli AH, Koldehoff M, Steckel NK, Trenschel R, Ottinger H, Beelen DW. Cytochrome P450 2C19 loss-of-function polymorphism is associated with an increased treatment-related mortality in patients undergoing allogeneic transplantation. Bone Marrow Transplant. 2007;40(7):659-64. doi:10.1038/sj.bmt. 1705786.

60. Kreyenberg H, Jarisch A, Bayer C, Schuster B, Willasch A, Strahm B, et al. NOD2/CARD15 gene polymorphisms affect outcome in pediatric allogeneic stem cell transplantation. Blood. 2011;118(4):1181-4. doi:10.1182/blood-2011-05-356451.

61. Hugot JP, Zaccaria I, Cavanaugh J, Yang H, Vermeire S, Lappalainen M, et al. Prevalence of CARD15/NOD2 mutations in Caucasian healthy people. Am J Gastroenterol. 2007;102(6): 1259-67. doi:10.1111/j.1572-0241.2007.01149.x.

62. Kugathasan S, Loizides A, Babusukumar U, McGuire E, Wang T, Hooper P, et al. Comparative phenotypic and CARD15 mutational analysis among African American, Hispanic, and White children with Crohn's disease. Inflamm Bowel Dis. 2005;11(7):631-8.

63. Khoury MJ, Coates RJ, Fennell ML, Glasgow RE, Scheuner MT, Schully SD, et al. Multilevel research and the challenges of 
implementing genomic medicine. J Natl Cancer Inst Monogr. 2012;2012(44):112-20. doi:10.1093/jncimonographs/lgs003.

64. Ciurea SO, Andersson BS. Busulfan in hematopoietic stem cell transplantation. Biol Blood Marrow Transplant J Am Soc Blood Marrow Transplant. 2009;15(5):523-36. doi:10.1016/j.bbmt. 2008.12.489.

65. Hassan M, Andersson BS. Role of pharmacogenetics in busulfan/ cyclophosphamide conditioning therapy prior to hematopoietic stem cell transplantation. Pharmacogenomics. 2013;14(1):75-87. doi:10.2217/pgs.12.185.

66. Ekhart C, Rodenhuis S, Smits PH, Beijnen JH, Huitema AD. Relations between polymorphisms in drug-metabolising enzymes and toxicity of chemotherapy with cyclophosphamide, thiotepa and carboplatin. Pharmacogenet Genomics. 2008;18(11):100915. doi:10.1097/FPC.0b013e328313aaa4.

67. Ekhart C, Doodeman VD, Rodenhuis S, Smits PH, Beijnen JH, Huitema AD. Influence of polymorphisms of drug metabolizing enzymes (CYP2B6, CYP2C9, CYP2C19, CYP3A4, CYP3A5, GSTA1, GSTP1, ALDH1A1 and ALDH3A1) on the pharmacokinetics of cyclophosphamide and 4-hydroxycyclophosphamide. Pharmacogenet Genomics. 2008;18(6):515-23. doi:10.1097/FPC. 0b013e3282fc9766.

68. Daly AK. Pharmacogenetics of the major polymorphic metabolizing enzymes. Fundam Clin Pharmacol. 2003;17(1):27-41.

69. Kropp S, Lichtinghagen R, Winterstein K, Schlimme J, Schneider U. Cytochrome P-450 2D6 and 2C19 polymorphisms and length of hospitalization in psychiatry. Clin Lab. 2006;52(5-6):237-40.

70. Melanson SE, Stevenson K, Kim H, Antin JH, Court MH, Ho VT, et al. Allelic variations in CYP2B6 and CYP2C19 and survival of patients receiving cyclophosphamide prior to myeloablative hematopoietic stem cell transplantation. Am J Hematol. 2010;85(12):967-71. doi:10.1002/ajh.21889.

71. Slattery JT, Risler LJ. Therapeutic monitoring of busulfan in hematopoietic stem cell transplantation. Ther Drug Monit. 1998;20(5):543-9.

72. Johnson L, Orchard PJ, Baker KS, Brundage R, Cao Q, Wang X, et al. Glutathione S-transferase A1 genetic variants reduce busulfan clearance in children undergoing hematopoietic cell transplantation. J Clin Pharmacol. 2008;48(9):1052-62. doi:10.1177/ 0091270008321940.

73. Bonifazi F, Storci G, Bandini G, Marasco E, Dan E, Zani E, et al. Glutathione transferase-A2 S112T polymorphism predicts survival, transplant-related mortality, busulfan and bilirubin blood levels after allogeneic stem cell transplantation. Haematologica. 2014;99(1):172-9. doi:10.3324/haematol.2013.089888.

74. Hahn T, Zhelnova E, Sucheston L, Demidova I, Savchenko V, Battiwalla $\mathrm{M}$, et al. A deletion polymorphism in glutathione-Stransferase mu (GSTM1) and/or theta (GSTT1) is associated with an increased risk of toxicity after autologous blood and marrow transplantation. Biol Blood Marrow Transplant J Am Soc Blood Marrow Transplant. 2010;16(6):801-8. doi:10.1016/j.bbmt.2010. 01.001 .

75. Muller P, Asher N, Heled M, Cohen SB, Risch A, Rund D. Polymorphisms in transporter and phase II metabolism genes as potential modifiers of the predisposition to and treatment outcome of de novo acute myeloid leukemia in Israeli ethnic groups. Leuk Res. 2008;32(6):919-29. doi:10.1016/j.leukres.2007.10.011.

76. Wang F, Liang YJ, Wu XP, Chen LM, To KK, Dai CL, et al. Prognostic value of the multidrug resistance transporter ABCG2 gene polymorphisms in Chinese patients with de novo acute leukaemia. Eur J Cancer. 2011;47(13):1990-9. doi:10.1016/j.ejca. 2011.03.032.

77. Pinto N, Ludeman SM, Dolan ME. Drug focus: pharmacogenetic studies related to cyclophosphamide-based therapy. Pharmacogenomics. 2009;10(12):1897-903. doi:10.2217/pgs.09. 134.
78. Chien JW, Zhang XC, Fan W, Wang H, Zhao LP, Martin PJ, et al. Evaluation of published single nucleotide polymorphisms associated with acute GVHD. Blood. 2012;119(22):5311-9. doi:10. 1182/blood-2011-09-371153.

79. Mullally A, Ritz J. Beyond HLA: the significance of genomic variation for allogeneic hematopoietic stem cell transplantation. Blood. 2007;109(4):1355-62. doi:10.1182/blood-2006-06030858.An important introduction to the idea of leveraging genomic technologies to perform larger scale SNP anlayes for the purpose of better genomic matching donors and recipients in hopes of achieving more favorable outcomes.

80. Gumperz JE, Barber LD, Valiante NM, Percival L, Phillips JH, Lanier LL, et al. Conserved and variable residues within the Bw4 motif of HLA-B make separable contributions to recognition by the NKB1 killer cell-inhibitory receptor. J Immunol. 1997;158(11):5237-41.

81. Giebel S, Locatelli F, Lamparelli T, Velardi A, Davies S, Frumento G, et al. Survival advantage with KIR ligand incompatibility in hematopoietic stem cell transplantation from unrelated donors. Blood. 2003;102(3):814-9. doi:10.1182/blood-2003-01-0091.

82. Ruggeri L, Capanni M, Urbani E, Perruccio K, Shlomchik WD, Tosti A, et al. Effectiveness of donor natural killer cell alloreactivity in mismatched hematopoietic transplants. Science. 2002;295(5562):2097-100. doi:10.1126/science.1068440.

83. Davies SM, Ruggieri L, DeFor T, Wagner JE, Weisdorf DJ, Miller JS, et al. Evaluation of KIR ligand incompatibility in mismatched unrelated donor hematopoietic transplants. Killer immunoglobulin-like receptor. Blood. 2002;100(10):3825-7. doi:10.1182/blood-2002-04-1197.

84. Bari R, Rujkijyanont P, Sullivan E, Kang G, Turner V, Gan K, et al. Effect of donor KIR2DL1 allelic polymorphism on the outcome of pediatric allogeneic hematopoietic stem-cell transplantation. J Clin Oncol Off J Am Soc Clin Oncol. 2013;31(30):378290. doi:10.1200/JCO.2012.47.4007.

85. Cooley S, Weisdorf DJ, Guethlein LA, Klein JP, Wang T, Marsh $\mathrm{SG}$, et al. Donor killer cell Ig-like receptor B haplotypes, recipient HLA-C1, and HLA-C mismatch enhance the clinical benefit of unrelated transplantation for acute myelogenous leukemia. J Immunol. 2014;192(10):4592-600. doi:10.4049/jimmunol. 1302517.

86. Weisdorf D, Cooley S, Devine S, Fehniger TA, DiPersio J, Anasetti $\mathrm{C}$, et al. T cell-depleted partial matched unrelated donor transplant for advanced myeloid malignancy: KIR ligand mismatch and outcome. Biol Blood Marrow Transplant J Am Soc Blood Marrow Transplant. 2012;18(6):937-43. doi:10.1016/j.bbmt.2011.11.024.

87. Cooley S, Weisdorf DJ, Guethlein LA, Klein JP, Wang T, Le CT, et al. Donor selection for natural killer cell receptor genes leads to superior survival after unrelated transplantation for acute myelogenous leukemia. Blood. 2010;116(14):2411-9. doi:10.1182/ blood-2010-05-283051.

88. Cooley S, Trachtenberg E, Bergemann TL, Saeteurn K, Klein J, Le CT, et al. Donors with group B KIR haplotypes improve relapse-free survival after unrelated hematopoietic cell transplantation for acute myelogenous leukemia. Blood. 2009;113(3):72632. doi:10.1182/blood-2008-07-171926.

89.• Venstrom JM, Pittari G, Gooley TA, Chewning JH, Spellman S, Haagenson M, et al. HLA-C-dependent prevention of leukemia relapse by donor activating KIR2DS1. N Engl J Med. 2012;367(9):805-16. doi:10.1056/NEJMoa1200503.A seminal KIR-HLA interaction article presenting evidence of donorrecipient interaction between genetic variation inf KIR2DS1 and HLA-C1 which impacts survival.

90. Uhrberg M, Parham P, Wernet P. Definition of gene content for nine common group B haplotypes of the Caucasoid population: KIR haplotypes contain between seven and eleven KIR genes. Immunogenetics. 2002;54(4):221-9. doi:10.1007/s00251-0020463-7. 
91. Hsu KC, Chida S, Geraghty DE, Dupont B. The killer cell immunoglobulin-like receptor (KIR) genomic region: gene-order, haplotypes and allelic polymorphism. Immunol Rev. 2002;190: $40-52$.

92. Hsu KC, Liu XR, Selvakumar A, Mickelson E, O'Reilly RJ, Dupont B. Killer Ig-like receptor haplotype analysis by gene content: evidence for genomic diversity with a minimum of six basic framework haplotypes, each with multiple subsets. J Immunol. 2002;169(9):5118-29.

93. Venstrom JM, Gooley TA, Spellman S, Pring J, Malkki M, Dupont B, et al. Donor activating KIR3DS1 is associated with decreased acute GVHD in unrelated allogeneic hematopoietic stem cell transplantation. Blood. 2010;115(15):3162-5. doi:10. 1182/blood-2009-08-236943.

94. Jia X, Han B, Onengut-Gumuscu S, Chen WM, Concannon PJ, Rich SS, et al. Imputing amino acid polymorphisms in human leukocyte antigens. PLoS One. 2013;8(6):e64683. doi:10.1371/ journal.pone.0064683.

95. Leslie S, Donnelly P, McVean G. A statistical method for predicting classical HLA alleles from SNP data. Am J Hum Genet. 2008;82(1):48-56. doi:10.1016/j.ajhg.2007.09.001.

96. Dilthey A, Leslie S, Moutsianas L, Shen J, Cox C, Nelson MR, et al. Multi-population classical HLA type imputation. PLoS Comput Biol. 2013;9(2):e1002877. doi:10.1371/journal.pcbi. 1002877.
97. Pillai NE, Okada Y, Saw WY, Ong RT, Wang X, Tantoso E, et al. Predicting HLA alleles from high-resolution SNP data in three Southeast Asian populations. Hum Mol Genet. 2014;23(16): 4443-51. doi:10.1093/hmg/ddu149.

98. Dignam JJ, Kocherginsky MN. Choice and interpretation of statistical tests used when competing risks are present. J Clin Oncol Off J Am Soc Clin Oncol. 2008;26(24):4027-34. doi:10.1200/ JCO.2007.12.9866.Cause-specific and sub-distribution hazards capture different relationships between variables and outcome. In this article the authors illustrate why this happens and when this occurs.

99. Fine JP, Gray RJ. A proportional hazards model for the subdistribution of a competing risk. J Am Stat Assoc. 1999;94(446):496-509. doi:10.1080/01621459.1999.10474144.

100. Logan BR, Zhang MJ, Klein JP. Regression models for hazard rates versus cumulative incidence probabilities in hematopoietic cell transplantation data. Biol Blood Marrow Transplant J Am Soc Blood Marrow Transplant. 2006;12(1 Suppl 1):107-12. doi:10. 1016/j.bbmt.2005.09.005.

101. Klein JP. Modelling competing risks in cancer studies. Stat Med. 2006;25(6):1015-34. doi:10.1002/sim.2246.

102. Latouche A, Allignol A, Beyersmann J, Labopin M, Fine JP. A competing risks analysis should report results on all cause-specific hazards and cumulative incidence functions. J Clin Epidemiol. 2013;66(6):648-53. doi:10.1016/j.jclinepi.2012.09.017. 